\title{
PELATIHAN PEMASANGAN DAN PERAWATAN AUDIO SYSTEM DI MUSHOLA BAITURROHMAN, TAMBORA- JAKBAR
}

\section{Ariyawan Sunardi ${ }^{1}$, Aripin Triyanto's), Nurkahfi Irwansyah ${ }^{3)}$, Woro Agus Nurtiyanto $^{4)}$, Awalludin Saputra'), Muhammad Koiru Ikhsan ${ }^{6}$.}

1,2,3,4,5,6Program Studi Teknik Elektro, Fakultas Teknik, Universitas Pamulang

\begin{abstract}
Abstrak
Masjid dan musholla adalah tempat beribadah untuk umat islam. Peralatan pendukungnya antara lain audio system. Audio system digunakan untuk mengumandangkan adzan serta iqomah. Bagian pendukung dari peralatan audio system, antara lain adalah amplifier, speaker, microphone dan kabel. Amplifier berguna untuk mengatur suara yang keluar ke speaker. Amplifier dilengkapi dengan pengaturan keseimbangan suara, bass dan treble yang masingmasing digunakan untuk memperjelas suara. Speaker digunakan untuk audio system di dalam maupun luar mushola. Microphone digunakan untuk penghubung dari amplifier ke speaker. Musholla Baiturrohman adalah salah satu tempat ibadah yang terletak di daerah TamboraJakarta Barat. Setelah melakukan survei di Musholla Baiturrohman, mahasiswa dan dosen melihat peralatan audio system yang sudah tidak berfungsi. Amplifier sudah tidak bisa dikontrol, microphone tidak mengeluarkan suara ke speaker dan instalasi listrik yang tidak aman dari jangkauan manusia. Kami melakukan pelatihan pemasangan dan perawatan audio system kepada para jamaah Musholla Baiturrohman. Pelatihan ini untuk meningkatkan kemampuan jamaah atau juga menghasilkan para ahli pemasangan dan perawatan audio system untuk berwirausaha. Metode pelatihan dengan ceramah, diskusi dan praktikum pemasangan audio system di Musholla Baiturrohman. Pelatihan perawatan juga dilakukan pembimbingan agar jamaah bisa menjaga lifetime dari perangkat audio system yang terpasang. Audio system Musholla Baiturrohman telah terpasang dan berfungsi dengan baik. Para jamaah mengikuti pelatihan ini dengan baik dan antusias
\end{abstract}

Keywords: audio system, musholla, Tambora, pemasangan dan perawatan.

\begin{abstract}
Mosques and prayer rooms are places of worship for Muslims. Supporting equipment such as audio systems. Audio system is used to echo the call to prayer and iqomah. The supporting parts of the audio system equipment include amplifiers, speakers, microphones and cables. Amplifier is useful for regulating the audio coming out to the speaker. Amplifiers are equipped with audio, bass and treble balance settings, each of which is used to clarify the audio. Speaker is used for audio systems inside and outside the mosque. Microphone is used to connect from amplifier to speaker. Baiturrohman Mosque is a place of worship that is located in the Tambora-West Jakarta area. After conducting a survey in the Baiturrohman Mosque, students and lecturers looked at the audio system equipment that was no longer functioning. Amplifiers can not be controlled, the microphone does not emit audio to the speakers and electrical installations that are not safe from human reach. We conducted training in installation and maintenance of audio systems for worshipers of the Musholla Baiturrohman congregation. This training is to improve the ability of pilgrims or also produce audio system installation and maintenance
\end{abstract}


experts for entrepreneurship. Training methods with lectures, discussions and practicum installation of audio systems in the Baiturrohman Mosque. Maintenance training is also carried out so that pilgrims can maintain the lifetime of the installed audio system. Baiturrohman Musholla Audio system has been installed and functioning properly. The pilgrims attended the training well and enthusiastically.

Keywords: audio system, mosque, tambora, instalastion and maintenance

Correspondence author: ariyawan sunardi, dosen00332@unpam.ac.id, South Tangerang, and Indonesia

\section{PENDAHULUAN}

\subsection{Latar Belakang}

Audio system dalam mushola digunakan sebagai salah satu sarana untuk memudahkan dalam pelaksanaan ibadah umat Islam. Dalam perencanaan pelatihan, pemasangan dan perawatan audio system, terdapat beberapa hal yang diperhatikan sebagai berikut: Luas bangunan mushola, ruang audio system, penempatan speaker, input penguat suara, Output pengeras suara, power output dan instalasi kabel sehingga mendapatkan hasil yang maksimal dalam keluaran suara.

Dari uraian diatas, kami selaku mahasiswa dan dosen dari Teknik Elektro Universitas Pamulang (UNPAM) mengadakan kegiatan Pengabdian Kepada Masyarakat (PKM). PKM bertujuan membagikan ilmu terkait teknik elektro dan memberikan contoh kegiatan pemasangan serta perawatan audio system pada Mushola Baiturrohman yang berlokasi di daerah Tambora Jakarta barat. Kegiatan tersebut sebagai bentuk kegiatan tri dharma universitas yang sifatnya berkelanjutan setiap semester.

Informasi dari masyarakat dan survey awal di Musholla Baiturohman - Tambora diperoleh masalah sebagai berikut:

1). Instalasi listrik Musholla Baiturrohman belum tersusun dengan rapi, hal ini beresiko terjadinya korsleting listrik.

2). Audio system di Musholla belum pernah diganti seusia dengan umur bangunan.

3). Suara pada speaker tidak jelas dan terputus-putus, adanya noise serta pernah mati disaat dipakai dalam waktu yang lama.

UNPAM tergabung dalam Yayasan Sasmita Jaya mempunyai visi "Bermutu dalam pengembangan pendidikan, pengabdian masyarakat, dan pengabdian terjangkau seluruh lapisan masyarakat, berlandaskan ridha Tuhan yang Maha Esa”. Sejalan dengan visi, UNPAM terus berkerjasama dengan berbagai pihak dalam pengembangan ilmu, teknologi, seni maupun institusi sebagai wujud pelaksanaan Tri Dharma Perguruan Tinggi yakni Pendidikan, Penelitian dan Pengabdian Masyarakat. UNPAM mempunyai berbagai stakeholder yakni pemerintah pusat, pemerintah propinsi, pemerintah kabupaten/kota, dunia usaha, swasta maupun dengan masyarakat.

Prodi Teknik Elektro UNPAM berkewajiban ikut serta membantu berbagai persoalan yang dihadapi masyarakat. Musholla Baiturrohman yang beralamat di Jl. 
Pelatihan Pemasangan Dan Perawatan Audio System Di Musholla Baitturohman, Tambora JakBar...(Ariyawan Sunardi)

Tambora III Kelurahan Tambora Jakarta Barat mempunyai permasalahann dengan audio system.

\subsection{Tujuan Pengabdian Kepada Masyarakat}

Secara khusus tujuan kegiatan PKM yang dilakukan Prodi Teknik Elektro UNPAM adalah:

1). Membagi ilmu pengetahuan yang didapatkan untuk menyelesaikan persoalan yang dihadapi jamaah Musholla Baiturrohman.

2). Membimbing jamaah Baiturrohman dalam pemasangan audio system.

3). Memberikan pengetahuan kepada jamaah Baiturrohman tentang cara merawat audio system supaya komponennya bertahan lama dan tetap keadaan baik.

4). Membimbing peningkatan kompetensi jamaah Baiturrohman dalam instalasi listrik khususnya audio system.

\subsection{Manfaat Pengabdian Kepada Masyarakat}

Kegiatan PKM berupa pelatihan pemasangan dan perawatan audio system kepada pengurus dan jamaah Musholla Baiturrohman. Manfaat yang diharapkan dari kegiatan PKM ini antara lain:

1). Membuka wawasan tentang permasalahan-permasalahan kelistrikan audio audio system yang dihadapi masyarakat secara umum.

2). Menambah pengetahuan dan ketrampilan dasar mengenai perbaikan dan perawatan peralatan audio audio system.

3). Memberikan nilai tambah berupa kemampuan menghitung biaya listrik.

4). Membuka wawasan mengenai beban-beban listrik yang hemat energi.

5). Mengetahui manajemen pemakaian listrik untuk audio audio system.

6). Sebagai bahan masukan bagi UNPAM, khususnya dalam mengembangkan kegiatan PKM yang berkaitan dengan jenis kegiatan Penyuluhan Masyarakat.

\section{METODE PELAKSANAAN}

Dalam pengabdian masyarakat ini pengabdi mengembangkan produk baru berupa pelatihan instalasi dan perawatan audio system di Musholla Baiturrohman. Metode pengabdian masyarakat dan pengembangan yang digunakan adalah model ADDIE yaitu analisis (Analysis), perancangan (Design), pengembangan (Development), implementasi (Implementation), dan evaluasi (Evaluation).

\subsection{Analysis (Analisis)}

Analisis dilakukan pada informasi kondisi fakta yang ada di Musholla Baiturrohman. Informasi didapatkan secara langsung dengan meninjau lokasi dan wawancara kepada pengurus serta jamaah Musholla Baiturrohman. Selanjutnya dilakukan analisis kebutuhan, materi, dan kurikulum pelatihan. Analisis kebutuhan berdasarkan permasalahan audio system yang dihadapi pengurus dan jamaah Musholla Baiturrohman. Sedangkan analisis materi berupa penentuan materi pelatihan pemasangan dan perawatan audio system yang akan disampaikan kepada 
masyarakat. Pada tahap akhir dilakukan analisis kurikulum yang meliputi analisis standar kompetensi, kompetensi dasar, serta indikator keberhasilan pelatihan yang ingin dicapai.

\subsection{Design (Perancangan)}

Tahap perancangan meliputi skema diagram audio system dan pembenahan instalasi listrik yang telah terpasang. Perancangan akan memudahkan langkah pemasangan dan perawatan audio system. Pengurus dan jamaah juga dipermudah dalam melakukan trouble shooting pasca pelatihan ini.

\subsection{Devolepment (Pengembangan)}

Instalasi audio system dan listrik yang telah terpasang sebelumnya dilakukan pengembangan untuk menjamin keamanannya. Tahap pengembangan meliputi review skema diagram audio system dan instalasi listrik yang telah terpasang. Segi keamanan instalasi listrik menjadi goal dari tahap pengembangan. Pengembangan modul pelatihan juga dilakukan pasca review dari dosen. Modul pelatihan harus mudah dipahami pengurus dan jamaah Musholla Baiturrohman karena modul ini sebagai acuan langkah ke depan.

\subsection{Implementation (Implementasi)}

Setelah dilakukan validasi oleh dosen dan dinyatakan layak untuk digunakan, maka dilakukan penerapan modul pelatihan kepada pengurus maupun jamaah Musholla Baiturrohman. Modul pelatihan meliputi pemasangan dan perawatan audio system berupa langkah-langkah teknis. Selain itu, penerepan wiring instalasi audio system juga dilakukan oleh pengurus dan jamaah Musholla Baiturrohman dengan bimbingan mahasiswa maupun dosen.

\subsection{Evaluation (Evaluasi)}

Sedangkan evaluasi kegiatan dilakukan setelah kegiatan pelatihan yaitu dengan cara verifikasi pemasangan dan perawatan audio system oleh tim dosen Teknik Elektro UNPAM. Tim PKM Teknik Elektro UNPAM meminta tanggapan pengurus dan jama'ah Musholla Baiturrahman terhadap kegiatan PKM yang dilakukan. Evaluasi juga dapat dilihat ketika sesi tanya jawab maupun praktikum pemasangan dan perawatan audio system.

\subsection{Realisasi Pemecahan Masalah}

Persiapan pelaksanaan diawali dengan kick-off meeting untuk menetapkan beberapa hal mendasar, antara lain: jenis kegiatan PKM, topik PKM, lokasi, dan waktu. Pada rapat koordinasi berikutnya, ditetapkan beberapa hal seperti: susunan acara, daftar peralatan, pembuatan alat peraga, dan anggaran biaya. Sasaran kegiatan PKM ini adalah pengurus musholla dan jamaah musholla baiturohman, di wilayah jl. Tambora Jakarta Barat. Sasaran yang diutamakan adalah pengurus musholla baiturohman yang notabene menghadapi permasalahan ketidak nyamanan beribadah 
dengan audio system yang sudah rusak dalam penggunaan sehari-hari. Oleh karena itu untuk kelancaran kegiatan PKM, Prodi Teknik Elektro UNPAM bekerjasama dengan pengasuh pengurus dan jamaah musholla. Melalui kegiatan penyuluhan ini diharapkan wawasan dan ketrampilan pengurus musholla mengenai masalah audio systemnya bisa dislesaikan dengan baik.

Permasalahan bahwa Musholla Baiturohaman sudah termasuk bangunan tua dan fasilitasnya untuk audio systemnya belum pernah di ganti sehingga disaat digunakan dalam keperluan Ibadah suaranya tidak jelas dan banyak suara terputus-putus, nois, bahkan pernah mati disaat dipakai dalam waktu yang lama. Sehingga kami juga di Izinkan dengan niat ingin membantu jamaah Musholla baiturohman agar dalam pelaksanaan ibadah bisa lancar, khusyuk dan pesan yang disampaikan bisa diterima dengan baik.

\subsection{Khalayak Sasaran}

Tempat, sasaran dan waktu pelaksanaan kegiatan adalah sebagai berikut:

Sasaran kegiatan : Pengurus DKM dan jamaah Musholla Baiturrohman

Tempat kegiatan : Musholla Baiturrohman

Waktu pelaksanaan : Jumat s.d. Minggu, 27 s.d. 29 September 2019

\subsection{Metode Kegiatan}

Metode yang digunakan dalam pengabdian masyarakat ini adalah melalui kegiatan:

1). Pelatihan

2). Pembuatan desain rangkaian audio system.

3). Penyusunan modul, bahan dan peralatanya.

4). Implementasi pemasangan dan perawatan.

Sedangkan evaluasi kegiatan dilakukan setelah kegiatan pelatihan kepada Pengurus dan Jama'ah Musholla Baiturrohman yaitu dengan cara verifikasi pemasangan dan perawatan audio system oleh tim dosen Teknik Elektro UNPAM. Juga meminta tanggapan pengurus dan jama'ah Musholla Baiturrohman terhadap kegiatan PKM yang dilakukan oleh Tim PKM Teknik Elektro Universitas Pamulang.

\section{HASIL DAN PEMBAHASAN}

\subsection{Tahap Persiapan}

Pada tahap ini, pelaksana melalukan survei lapangan untuk menganalisa kebutuhan komponen yang diperlukan untuk kebutuhan pemasangan audio system. Dalam tahap ini dicari permasalahan-permasalahan kelistrikan yang sering dihadapai oleh pengurus musholla. Dari hasil pendataan tersebut kita susun dan pelajari untuk melakukan persiapan mencari kmponen yang di butuhkan yang akan dipasang dalam kegiatan PKM. Dilanjutkan dengan persiapan peralatan dan perangkat yang dibutuhkan sebagai alat untuk pemasangan audio system nya. 


\subsection{Tahap Pelaksanaan}

Pelaksanaan PKM dilaksanakan pada hari Jumat - Minggu, 27-29 September 2019 pukul 19.00 - 22.00 WIB dan 08.00 - 17.00 WIB di Musholla Baiturohman jl. Tambora III Gg. 4 RT/RW 05/06 Jakarta Barat. Acara diawali dengan pemberian sambutan-sambutan dari pihak-pihak terkait, dari ketua DKM Bpk Syarif Ridwan Dilanjutkan dengan pengurus Musholla Bpk Sukandar dan dilanjutkan dengan pemberian sambutan dari perwakilan program studi Teknik Elektro UNPAM, Khoiru Ihksan, Samsuryono dan Syarifudin selaku perwakilan mahasiswa pelaksana PKM Prodi Teknik Elektro UNPAM.

Setelah rangkaian pelaksanaan pemasangan audio system selesai, acara dilanjutkan dengan penyulluhan dan bimbingan mengenai pemasangan, perawatan, dan perbaikan Audio system oleh para mahasiswa dan dosen pembimbing.

Dengan berakhirnya acara penyerahan simbolis audio system, yang dilanjutkan dengan pemberian berupa berita acara kepada DKM Musholla Baiturohman dan perwakilan pengurus Musholla, maka seluruh rangkaian acara penyuluhan masyarakat pada kegiatan PKM ditutup.

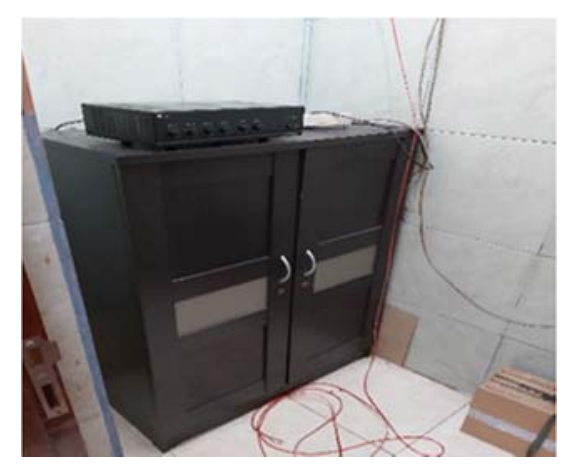

Gambar 1 Ruangan Audio system

Pelaksaan hari pertama kita merapikan dahulu di ruangan Amplifiernya karena sebagai pusat kontrol untuk Audio systemnya. Beberapa instalasinya sudah rantas dan kabelnya sudah banyak yg lecet karena sudah lama dan alur instalasinya tidak rapi sehingga pengerjaanya membutuhkan waktu yg lumayan lama karena harus mencari jurusan dan arah instalasinya.

Setelah lama kita pelajari instalasinya dan kita membagi tugas agar pengerjaanya lebih cepet efesien serta tetap mengutakan keselamatan kerjanya. Setelah job desk sudah kita bagi dan lebih spesifik kita melakukan tugas masingmasing sehingga instalasi listrikya bisa dipelajari dan mengganti jalur instalasi utamanya yang lebih rapi dan safety. 
Pelatihan Pemasangan Dan Perawatan Audio System Di Musholla Baitturohman, Tambora JakBar...(Ariyawan Sunardi)

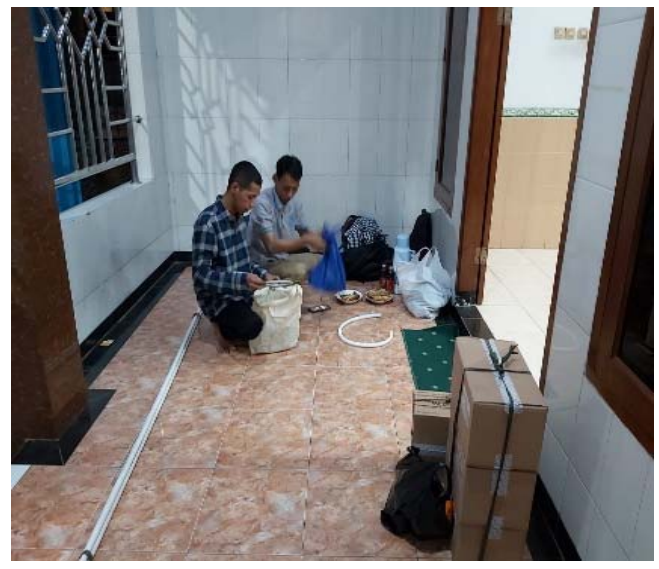

Gambar 2 Persiapan Alat

Pelaksanaan pertama kalinya pembawaan komponenya audio system dan menyiapkan peralatanya agar dalam pengerjaanya lebih mudah dan sudah tersiapkan dari awal.

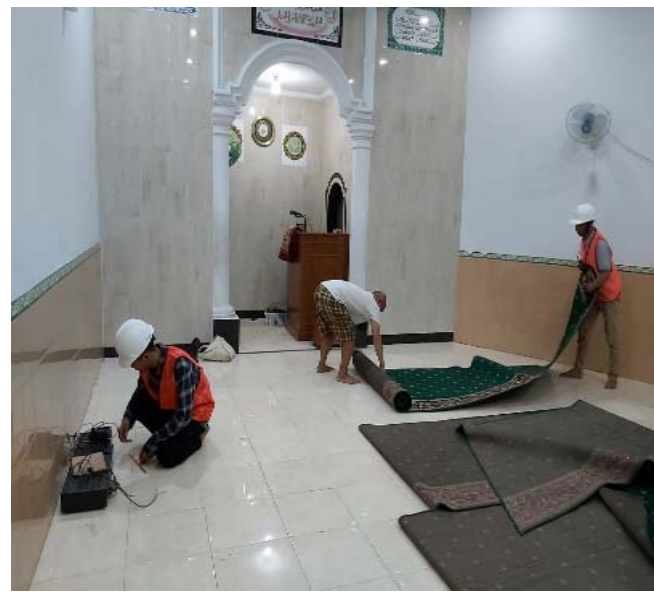

Gambar 3 Perapian Lokasi

Perapian dahulu untuk area ruangan mushollanya agar tidak kotor disaat waktu pengerjaanya dibantu dengan pengurus musholla Bpk Sukandar.

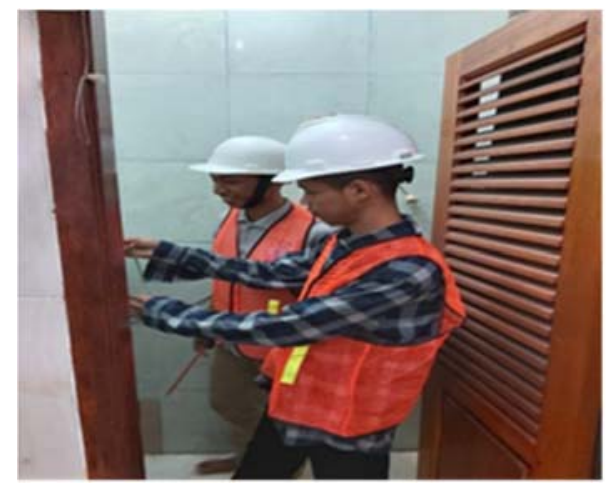

Gambar 4 Perapian Ruangan Control 
Perapian di ruangan control atau di ruangan Amplifiernya agar pada saat pembutan jalur barunya lebih mudah dan lebih rapi instalasinya.

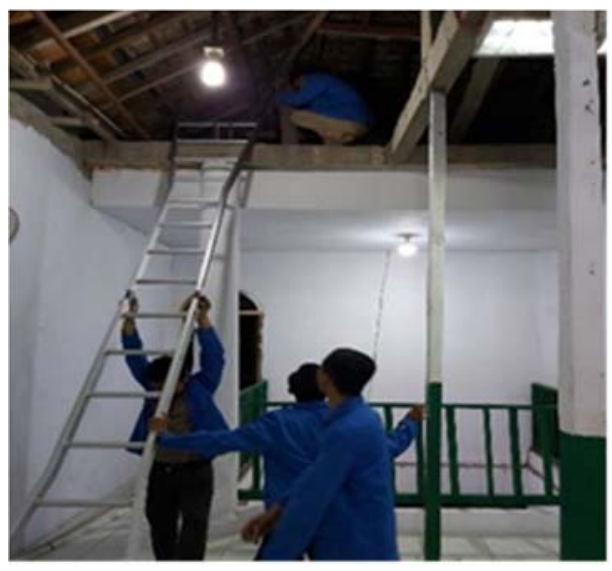

Gambar 5 Instalasi Listrik

Pencarian jalur instalasi lamanya untuk diganti pembuatan jalur barunya karena instalasi kabel listrik yang lamanya sudah banyak yang rantas dan diganti yang baru supaya lebih aman dan tahan lama. Gambar diatas proses pencarian jalus instalasi untuk Amplifiernya yang jalur lamanya berantakan tidak rapi dan tidak terisolasi dengan baik sehingga jalur instalasinya harus di rubah mencari jalur baru dan mengganti instalasi dan kabel listrik yang baru. Dengan waktu kurang lebih 3 jam kita berproses memperbakinya syukur dapat diselesaikan juga dan berlanjut ke pemasangan audio systemnya.

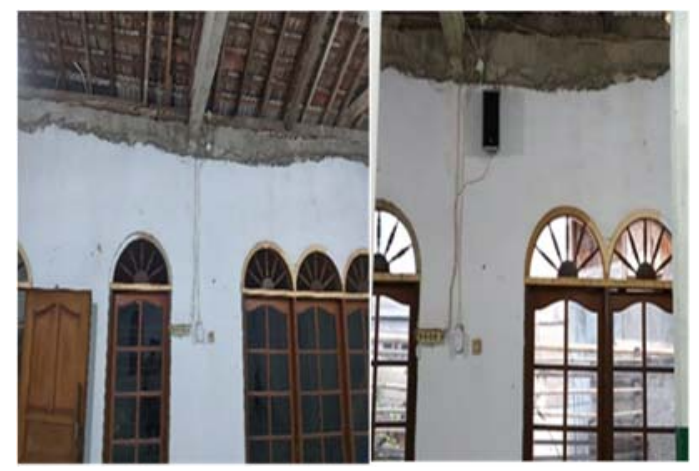

Gambar 6 Sebelum dan Sesudah Pemasangan Speaker

Pelaksanaan hari kedua yaitu pemasangan Audio system di lantai 2. Lantainya sedikit lebih tinggi sehingga pemasanganya audio system mengalami sedikit terkendala karena tangga yg disiapkan kurang menjangkau pekerjaan. Jadi kita perlu menambah orang di bagian ini untuk membantu perkuatan tangganya supaya lebih safety atau lebih aman. Dari mulai mengoneksi instalasi dari power amlifiernya yang areanya sempit sehingga hanya 1 orang saja yg bisa masuk dan mengerjakanya. 


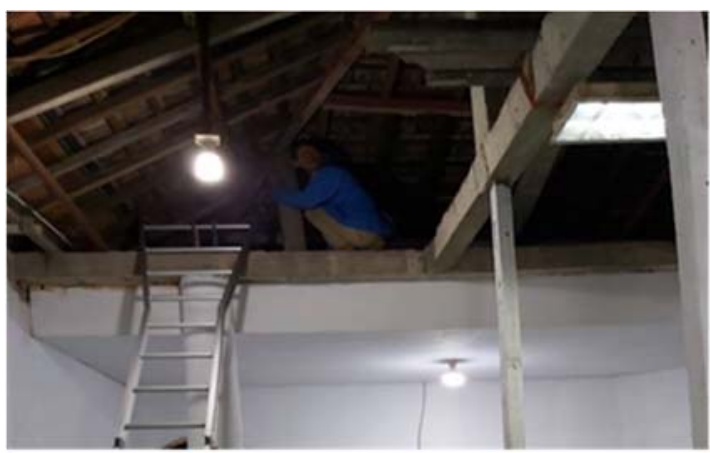

Gambar 7 Koneksi Instalasi

Setelah penyambungan kabel instalasi audionya dari Amplifiernya sudah tersambung tinggal penarikan jalur kabel ke tempat audionya dipasang. Pada saat pemasangan isolasinya kabel listriknya atau pipa pvcnya, balokan struktur bangunanya sudah tua dan kelihatan tidak kuat sehingga kita sangat berhati-hati menghindari pada saat pemasangan clampnya balokan tidak mengalami krek atau retak karena ukuranya juga tidak terlalu besar.

Hari ketiga pelaksanaan pemasangan Audio system tinggal dilantai 1 ruangan utama yang dipakai untuk beribadah setiap hari. Disini ruanganya di pasang audionya 2 tempat yaitu kanan dan kiri sisi ruangan imam sholat. Dilantai 1 ini meski bangunan termasuk struktur lama tapi kita kesulitan di pengeboranya dinabolt karena struktur dindingnya masih bagus dan sangat keras. Hingga kita bergantian sampai beberapa orang mencoba bergantian pengoboran dindingnya untuk dinabolt tempat hanger audionya karena kerasnya dinding musholla tsb. Dengan lamanya kita mencoba dan bergantian pengeboranya ke dinding aqirnya bisa slesai juga dan instalasi kabelnya juga tidak terlalu jauh dari ruangan Amplifiernya sehingga lebih mudah dibandingkan di lantai duanya.

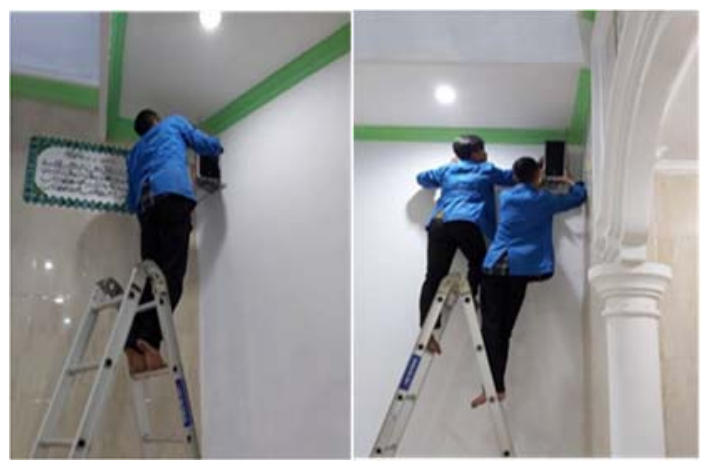

Gambar 8 Pemasangan Speaker

Sebagai acara penutupan kita tutup dengan doa bersama dan dokumentasi foto barsama Ibu kepala Desa dan masyarakat sekitar. Semoga dengan berlangsunya progam PKM ini dapat membantu masyarakat dan sebagai wadah bersosial antara mahasiswa dan masyarakat Selain itu juga akan didapatkan jalinan kerjasama yang bagus antara masyarakat sebagai stakeholder UNPAM. 


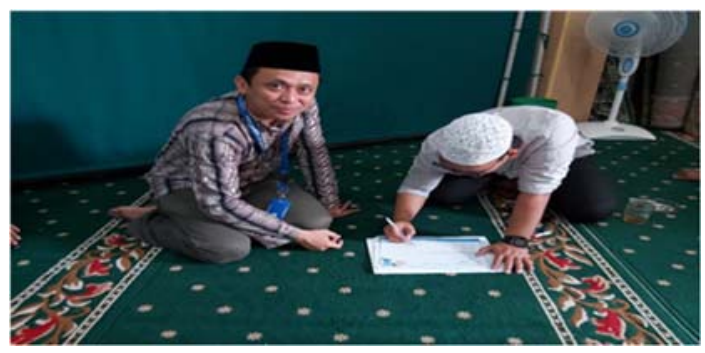

Gambar 9 Tanda Tangan Berita Acara PKM

Penandatangan berita acara ini sebagai bukti bahwa pelaksanaan tugas mahasiswa Unpam PKM sudah slesai dan dapat di terima di masyarakat dengan di tandatanginya berita acara bersama ketua DKM Bpk Syarif Ridwan. Sebagai rasa wujud syukur dan symbol sebuah kepedulian dari pihak yang terlibat dalam pelaksanaan progam PKM tsb.

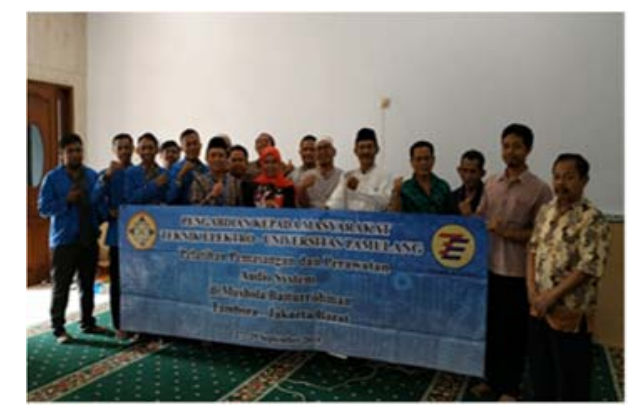

Gambar 10 Acara Foto Bersama

\section{SIMPULAN}

Kegiatan PKM yang berbentuk dalam pelatihan pemasangan dan perawatan audio system ini berjalan lancar. Antusiasme peserta begitu besar, banyak pertanyaan dilontarkan peserta terkait masalah kelistrikan audio system yang sering dihadapi.. Begitu juga peran serta aktif pengurus dan jamaah Musholla Baiturrohman dalam praktikum yang langsung dibimbing mahasiswa beserta dosen. Berdasarkan hasil wawancara dan evaluasi, seluruh pengurus dan jamaah musholla Baiturohman merasakan manfaat materi yang disampaikan. Pelaksanaan kegitan PKM dapat disimpulkan berhasil sampai tahap meningkatkan minat masyarakat dalam mempelajari teori-teori dasar dan ilmu-ilmu praktis yang terkait dengan kelistrikan pada audio system. Keberhasilan ini ditunjukkan antara lain : adanya komitmen bersama untuk menggunakan audio system secara benar dan hemat energi, kesadaran peserta untuk mengutamakan keamanan dan keselamatan penggunaan audio system, kesesuaian materi dengan kebutuhan masyarakat dan jamaah dalam menunaikan beribadah setiap hari, respon positif dari peserta untuk meningkatkan keahlian perawatan audio systemnya dalam keseharianya dan ketertarikan kerjasama antara jamaah musholla untuk dijadikan binaan oleh prodi Teknik Elektro UNPAM dalam pengembangan kewirausahaan di beberapa sektor industri. 
Pelatihan Pemasangan Dan Perawatan Audio System Di Musholla Baitturohman, Tambora JakBar...(Ariyawan Sunardi)

\section{DAFTAR PUSTAKA}

Rehena, N. S. E., Mamahit, D. J. \& Wuwung, J. O. (2014). Rancang Bangun Audio Mixer Yang Dilengkapi Dengan Desibel Peak Meter. Ejournal Teknik Elektro dan Komputer UNSRAT Manado, ISSN: 2301- 8402.

Wibowo, H. Y., Rante, H., A. S. KH. (2011). Implementasi Teknik Audio Effect Dan Voice Over Dalam Pembuatan Video Dokumenter Perlindungan Anak Di Kawasan Dolly. Institut Teknologi Sepuluh Nopember (ITS). Surabaya: ITS.

Gunawan, D. (2010). "Pengaturan Masukan Mixer Audio Digital 2 Berbasis Time Division Multiplexing (TDM). Skripsi Jurusan Teknik Elektro UNIKOM. Bandung: UNIKOM.

Waluyanti, Sri. (2008). Teknik Audio Video. Yogyakarta: Direktorat Pembinaan SMK. 